\title{
Implementasi Web Application Firewall Dalam Mencegah Serangan SQL Injection Pada Website
}

\author{
Bangkit Wiguna ${ }^{1}$, Wahyu Adi Prabowo ${ }^{2}$, Ridho Ananda ${ }^{3}$ \\ ${ }^{1,2,3}$ Teknik Informatika, Fakultas Informatika, Insitut Tekbologi Telkom Purwokerto \\ 1,2,3 J1. D. I. Pandjaitan No.128 Purwokerto Selatan, Jawa Tengah Indonesia 53147 \\ e-mail: ${ }^{1} 16102080 @$ ittelkom-pwt.ac.id, ${ }^{2}$ wahyuadiprabowo@ittelkom-pwt.ac.id, \\ 3ridho@ittelkom-pwt.ac.id
}

\begin{abstract}
Abstrak
Dalam beberapa tahun terakhir perkembangan teknologi informasi menjadi semakin pesat, perkembangan ini membuat segala aktifitas dan pekerjaan menjadi lebih mudah, seperti halnya untuk mengakses berita maupun informasi. Salah satu media yang sering digunakan untuk menemukan berbagai macam informasi pada saat ini yaitu website. Banyaknya website yang ada pada saat ini membuat ia sering dijadikan sasaran berbagai jenis serangan web yang beragam seperti SQL injection. Sehingga diperlukan suatu sistem yang mampu memberikan solusi dalam pengamanan website. Pada penelitian ini menggunakan metode web application firewall karena metode ini mampu untuk menjadi security system dalam mengamankan suatu website dari serangan. Metode web application firewall dilakukan dengan memblokir serangan sql injection yang masuk berdasarkan konfigurasi rules yang telah ditetapkan. Dan dari hasil penelitian ini serangan SQL injection yang telah diujicobakan pada website berhasil diblokir sehingga membuat website menjadi aman dari serangan tersebut. .
\end{abstract}

Kata kunci: Keamanan, Serangan Web, SQL injection, Website, Web Application Firewall.

\section{Abstract}

In the last few years the development of information technology has become increasingly rapid, this has made all activities and jobs easier, such as accessing news and information. One of the media that is often used to find various kinds of information at this time is the website. The large number of websites that exist today makes it a frequent target of various types of web attacks such as SQL injection. So we need a system that is able to provide solutions in securing a website. This research uses a web firewall application method because this method is able to become a security system on a website from attacks. The firewall web application method is carried out by the sql injection attack method which is entered based on predefined rules. And from the results of this study, the SQL injection attack that was tested on the website was successful so that it made the website safe from these attacks.

Keywords: Security, Web Attack, SQL injection, Website, Web Application Firewall.

\section{Pendahuluan}

Dalam beberapa tahun terakhir perkembangan teknologi informasi menjadi semakin pesat, perkembangan ini membuat segala aktifitas dan pekerjaan menjadi lebih mudah, seperti halnya untuk mengakses berita maupun informasi. Salah satu media yang sering digunakan untuk menemukan berbagai macam informasi pada saat ini yaitu website. Website merupakan aplikasi yang tersimpan pada web server dan dieksekusi oleh web server. Web server berfungsi menerima permintaan (request) berupa halaman web melalui HTTP atau HTTPS dari pengguna yang dikenal dengan web browser dan mengirimkannya kembali (response) hasilnya dalam bentuk halaman-halaman web yang umumnya berbentuk dokumen $H T M L$ [1]. Seiring dengan berkembangnya zaman website pun juga turut ikut berkembang dan menjadi populer dikalangan masyarakat, banyaknya website yang ada pada saat ini membuat ia sering dijadikan sasaran 
berbagai jenis serangan web oleh pengguna yang memiliki niat jahat [2]. Karena pada website biasanya tersimpan data data penting pengguna, seperti contohnya data data pribadi yang bisa saja berakibat fatal apabila disalahgunakan.

Ada banyak jenis serangan web pada saat ini [3], salah satu jenis serangan web yang paling populer yaitu SQL injection, Menurut referensi dari buku yang ditulis oleh J. Clarke pada tahun 2012 dengan judul "SQL Injection Attacks and Defense" [4], serangan SQL injection merupakan jenis serangan injeksi ke suatu aplikasi web, dimana penyerang dapat mengeksekusi pernyataan sql yang berbahaya. Sedangkan menurut open web application security (OWASP) $S Q L$ injection merupakan suatu teknik yang sering digunakan oleh attacker untuk menerobos ke suatu web secara ilegal. SQL injection digunakan oleh attacker untuk mengirimkan perintah perintah $S Q L$ melalui $U R L$ yang nantinya dieksekusi oleh web server. Dari informasi tersebut injection termasuk dalam 10 risiko keamanan web paling kritis [5]. Adapun contoh nyata kasus serangan SQL injection yang terjadi baru baru ini, seperti yang diberitakan oleh situs www.liputan6.com bahwa telah terjadi kasus peretasan oleh sejumlah hacker asal surabaya yang berhasil membobol ratusan situs web luar negeri pada 44 negara dengan menggunakan teknik SQL injection [6]. Selain itu menurut laporan dari Imperva pada tahun 2018, kerentanan serangan pada website yang paling tinggi didominasi oleh serangan SQL injection yaitu $19 \%$ atau sebanyak 3.294 kasus dari total keseluruhan serangan yang terjadi, hal ini menjadikan serangan $S Q L$ injection mengalami peningkatan yang cukup pesat daripada tahun sebelumnya yang hanya tercatat sebanyak 896 kasus saja [7]. Dari berbagai informasi tadi, diketahui bahwa serangan SQL injection masih menjadi masalah yang belum dapat teratasi secara maksimal, sehingga masih membutuhkan penanganan khusus terhadap masalah ini. SQL injection pun diketahui memiliki beberapa tipe serangan yang beragam [8], diantaranya yaitu TauntologyBased, Incorrect Queries, Stored Procedure Injection, Piggy Backed, Union-Based, ErrorBased, dan yang terakhir yaitu Blind SQL Injection.

Dalam mengatasi serangan $S Q L$ injection, diketahui ada beberapa cara untuk mencegah serangan tersebut [9]. Seperti yang telah dilakukan oleh peneliti sebelumnya guna mengatasi permasalahan serangan ini. Seperti halnya yang telah dilakukan oleh Asish Kumar Dalai, dkk (2017), menggunakan metode server side code modification untuk mencegah serangan SQL injection [10]. Metode ini bekerja dengan cara memblokir query inputan jika berdasarkan perbandingan dengan query asli menimbulkan hasil yang berbeda. Namun metode ini masih terdapt kekurangan yaitu belum bisa melakukan deteksi serangan yang dilakukan menggunakan tools SQL injection.

Utpal Upadhyay, dkk (2016), melakukan penelitian untuk mencegah serangan $S Q L$ injection menggunakan metode SNORT dan Honeypot [11]. Metode ini bekerja dengan cara membandingkan permintaan pengguna dengan existing attack signature, dan jika terdapat kecocokan maka pengguna akan diteruskan menuju halaman yang telah dibuat menggunakan honeypot untuk mengelabuhi penyerang. Adapula penelitian yang dilakukan untuk mengetahui metode terbaik yang layak digunakan untuk mencegah serangan SQL injection seperti yang dilakukan oleh Arianit Maraj, dkk (2017), yang menguji coba beberapa metode untuk mendapatkan metode terbaik dalam mengatasi serangan tersebut [12]. Dari penelitian tersebut di diketahui metode terbaik yaitu dengan menggunakan firewall yang diterapkan sebagai security system pada website, hasil ini didapatkan berdasarkan hasil ujicoba tools SQL injection yang digunakan tidak mendapatkan informasi apapun dari website yang menerapkan security system tersebut.

Dari beberapa penelitian yang telah dilakukan oleh peneliti sebelumnya, secara garis besar, solusi yang diberikan yaitu dengan menerapkan security system yang dapat mencegah tiap serangan $S Q L$ injection yang masuk kedalam website, baik itu serangan yang dieksekusi secara manual maupun serangan yang dieksekusi secara otomatis menggunakan tools. Berdasarkan solusi tersebut, belum ada security system yang dapat benar benar melakukan penanganan terhadap serangan $S Q L$ injection ini.

Pada penelitian ini penulis menggunakan metode Web Application Firewall. Web Application Firewall [13] dapat digunakan sebagai system yang dapat mencegah serta 
mendeteksi serangan SQL injection degan menggunakan detection rules yang telah ditetapkan untuk dapat memblokir akses bagi penyerang yang menginputkan permintaan berbahaya ataupun penyerang yang mengeksekusi serangan SQL injection menggunakan tools kedalam website [14]. Penelitian ini ditulis dengan tujuan untuk mengatasi serta melakukan pencegahan terhadap serangan SQL injection yang dieksekusi oleh attacker kedalam website, sehingga data yang tersimpan pada database website menjadi lebih aman dan terhindar dari sabotase serta pencurian data yang dilakukan oleh attacker, dengan adanya penelitian ini juga bertujuan untuk meminimalisir terjadinya serangan $S Q L$ injection yang saat ini serangan tersebut masih menjadi salah satu serangan web populer yang sering digunakan, karena pada dasarnya $S Q L$ injection masih tergolong sebagai salah satu masalah yang apabila terus dibiarkan dan tidak dicegah maka akan mengakibatkan dampak yang merugikan terhadap pengguna maupun pihak pengelola website.

\section{Metode Penelitian}

Pada tahapan penelitian ini penulis menjabarkan langkah-langkah yang akan dilaksanakan pada penelitian ini. Berikut tahapan yang dilakukan, adzalah sebagai berikut :

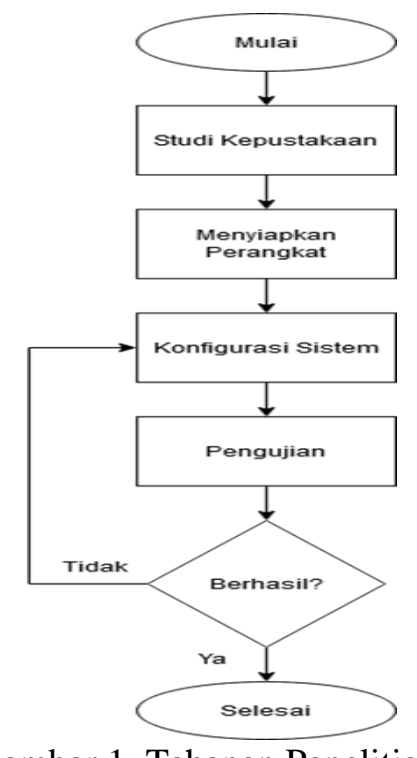

\subsection{Studi Kepustakaan}

Gambar 1. Tahapan Penelitian

Pada tahap ini dilakukan studi pustaka guna mendapatkan landasan pemikiran dan cara untuk menunjang penelitian yang dibuat dengan cara mencari referensi seperti buku, artikel, jurnal, ataupun semacamnya yang mempunyai keterkaitan dengan penelitian yang dibuat.

\subsection{Menyiapkan Perangkat}

Tahapan selanjutnya adalah menyiapkan perangkat maupun tools [15] yang dibutuhkan untuk menunjang penelitian ini diantaranya yaitu :

Tabel 1. Spesifikasi Perangkat

\begin{tabular}{ccc}
\hline & Client & Server \\
\hline CPU & 2 Core CPU & 2 Core CPU \\
RAM & 4 GB RAM & 1 GB Ram \\
Storage & 1 TB HDD Storage & 30 GB SSD Storage \\
OS & OS Windows 10 64 Bit & Ubuntu 18.04 64 Bit \\
Device & Laptop Asus A456U & VPS Pro \\
\hline
\end{tabular}


Tabel 2. Tools yang digunakan

\begin{tabular}{|c|c|c|}
\hline No & Perangkat & Keterangan \\
\hline 1 & Modsecurity & $\begin{array}{l}\text { Tools yang digunakan sebagai } \\
\text { WAF }\end{array}$ \\
\hline 2 & SQLMap & $\begin{array}{l}\text { Tools yang digunakan untuk } \\
\text { mengeksekusi serangan } S Q L \\
\text { injection }\end{array}$ \\
\hline 3 & JSqlinjection & $\begin{array}{l}\text { Tools yang digunakan untuk } \\
\text { mengeksekusi serangan } S Q L \\
\text { injection }\end{array}$ \\
\hline 4 & Web Stress & $\begin{array}{l}\text { Tools yang digunakan untuk } \\
\text { uji coba performansi pada } \\
\text { website }\end{array}$ \\
\hline 5 & LAMPP Stack & $\begin{array}{c}\text { Kumpulan perangkat yang } \\
\text { digunakan untuk membangun } \\
\text { website }\end{array}$ \\
\hline
\end{tabular}

\subsection{Konfigurasi Sistem}

Tahap ini merupakan tahapan untuk konfigurasi yang dibutuhkan pada penelitian ini. Konfigurasi ini penulis lakukan pada server yang digunakan. Adapun konfigurasi terebut meliputi beberapa tahapan yaitu :

1. Konfigurasi Apache2

Pada tahapan ini konfigurasi yang dilakukan bertujuan untuk menghubungkan website dengan apache2 yang bertindak sebagai web server pada penelitian ini, tahapan konfigurasi ini diperlukan agar website nantinya dapat diakses oleh user.

2. Konfigurasi MySQL

Selanjutnya penulis melakukan konfigurasi pada $M y S Q L$ yang digunakan sebagai database pada penelitian ini, konfigurasi yang dilakukan meliputi, pembuatan database serta memberikan priviledges pada user yang bersangkutan agar dapat mengakses database tersebut.

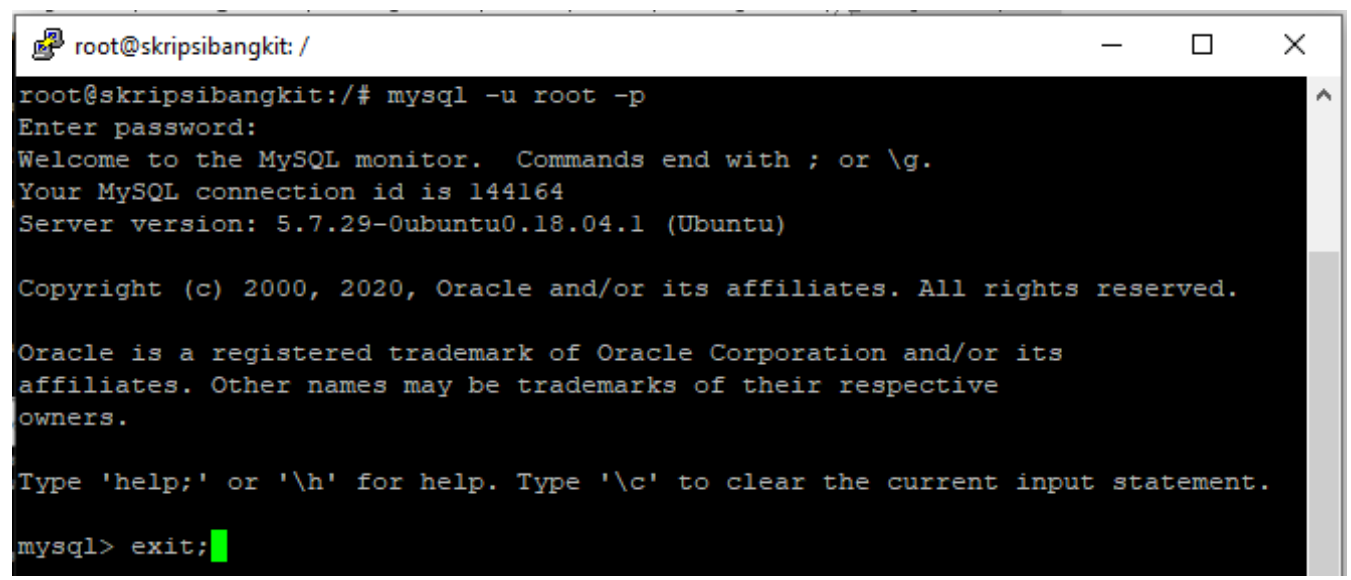

Gambar 2. Konfigurasi MySQL

3. Konfigurasi PHPMyadmin

Selanjutnya penulis melakukan konfigurasi pada PHPMyAdmin yang digunakan sebagai interface untuk mengelola database MySQL pada penelitian ini. Adapun konfigurasi ini 
dilakukan agar PHPMyAdmin nantinya dapat berjalan pada Apache2 yang sebelumnya juga telah dikonfigurasikan.

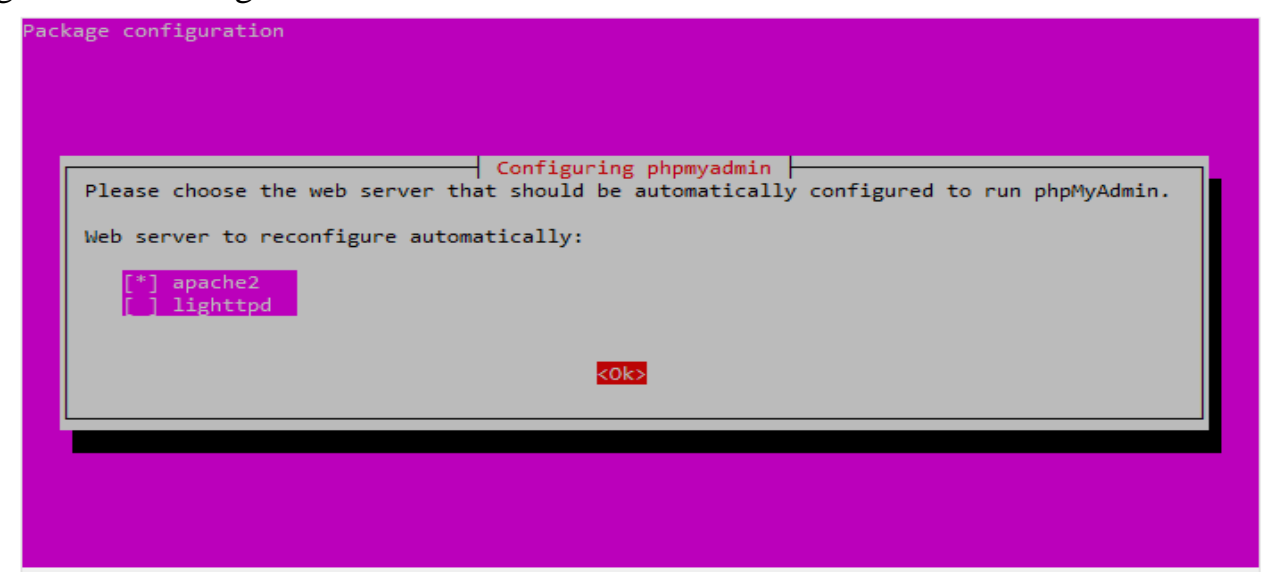

4. Konfigurasi PHP

Gambar 3. Konfigurasi PHPMyAdmin

Pada tahap ini penulis melakukan instalasi dan konfigurasi $P H P$ yang digunakan sebagai sebagai bahasa pemprograman server side scripting dari website yang digunakan pada penelitian ini. Tahapan ini dapat dilakukan dengan cara mengetikan perintah "sudo apt-get install php libapache2-mod-php php-MySQL".

5. Konfigurasi WAF Modsecurity

Tahap konfigurasi WAF modsecurity merupakan tahapan selanjutnya yang harus dilakukan, WAF modsecurity merupakan web application firewall yang digunakan pada penelitian ini.

Perlindungan website yang diberikan oleh modsecurity terhadap serangan dilakukan secara real-time [16], modsecurity juga mendefinisikan aturan mengenai data HTTP yang dimana aturan tersebut akan memiliki akses ke informasi HTTP header secara penuh [17].

Adapun konfigurasi ini dilakukan dengan memodifikasi file "modsecurity.conf" yang terletak didalam direktori "/etc/modsecurity/". Konfigurasi ini dilakukan dengan mengubah SecRuleEngine yang sebelumnya DetectionOnly menjadi On agar Modsecuirty dapat menjalankan rules yang nantinya akan dibuat.

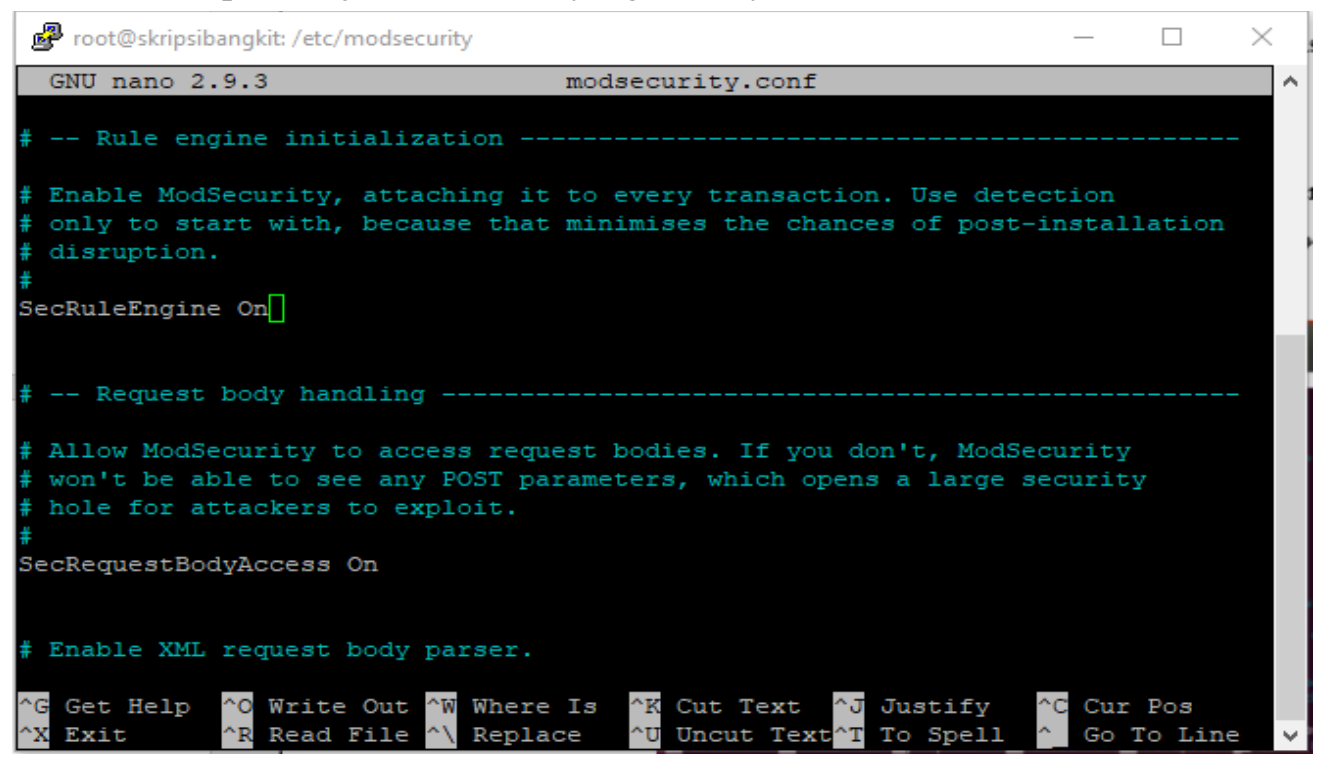

Gambar 4. Konfigurasi Modsecurity 
6. Konfigurasi Rules Modsecurity

Selanjutnya yaitu mengonfigurasikan rules Modsecurity karena Modsecurity tidak akan berjalan jika tidak adanya rules. Adapun untuk membuat rules dapat dilakukan dengan cara mengetikan "SecRule VARIABLES OPERATOR [ACTIONS]". Rules yang dibuat diletakan pada directory Modsecurity agar dapat bekerja [18].

Tabel 3. Penjelasan rules yang dibuat

\begin{tabular}{cc}
\hline Perintah & Penjelasan \\
\hline SecRule & Perintah dasar untuk membuat rule. \\
VARIABLES & Inisialisasi variable yang akan dicek. \\
OPERATOR & Inisialisasi operator apa saja yang \\
akan diawasi. \\
[ACTIONS] & Inisialisasi tindakan apa saja yang \\
akan dilakukan.
\end{tabular}

\subsection{Pengujian}

Pada tahapan ini akan dilakukan pengujian pada system untuk mengetahui apakah system yang telah diterapkan dapat berfungsi dengan baik. Pengujian dilakukan dengan 2 tahapan berbeda, yaitu pengujian serangan dari attacker terhadap website, serta pengujian performansi pada website yang telah diterapkan web application firewall didalamnya.

\section{Hasil dan Pembahasan}

Berdasarkan tahapan penelitian diatas, maka dapat diperoleh hasil pengujian pada penelitian ini, yaitu :

\subsection{Tahap Implementasi}

Selanjutnya penulis melakukan konfigurasi rules modsecurity yang digunakan sebagai web application firewall pada penelitian ini. Rules ini akan bekerja dengan cara mengawasi operator yang telah didefinisikan, dan akan membatasi akses sesuai dengan action yang ditetapkan apabila operator tersebut terdeteksi, berikut merupakan potongan code dari rule yang dibuat :

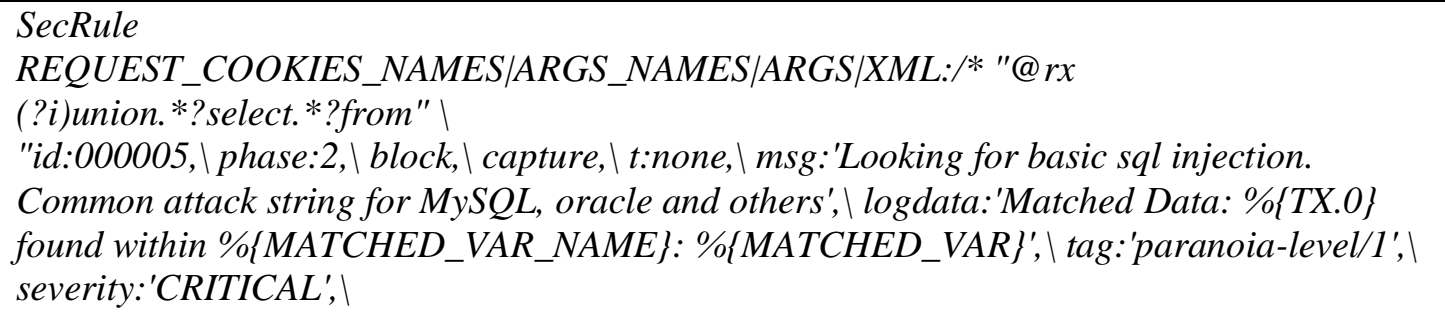

Tabel 4. Penjelasan rules yang dibuat

\begin{tabular}{cc}
\hline Perintah & Penjelasan \\
\hline Secrule & Membuat rule \\
& $\begin{array}{c}\text { Variabel yang akan dicek oleh rule } \\
\text { ini, yaitu Request Cookies Names, } \\
\text { Argumen Names, Argumen, serta }\end{array}$ \\
REQUEST_COOKIES & XML
\end{tabular}




\begin{tabular}{|c|c|}
\hline Perintah & Penjelasan \\
\hline $\begin{array}{c}\text { @rx } \\
\text { (?i)union.*?select.*?from }\end{array}$ & $\begin{array}{l}\text { Operator yang digunakan oleh rule } \\
\text { ini untuk mendefinisikan kata yang } \\
\text { akan ditolak seperti union, select, } \\
\text { from. }\end{array}$ \\
\hline id:000005, \phase:2 & Id unik rule ini, dengan phase 2 . \\
\hline block,\capture & $\begin{array}{c}\text { Memblokir dan mengcapture } \\
\text { operator yang telah di definisikan } \\
\text { jika terdeteksi. }\end{array}$ \\
\hline t:none & $\begin{array}{l}\text { Menghilangkan semua fungsi } \\
\text { transformasi yang berkaitan pada } \\
\text { rule ini. }\end{array}$ \\
\hline$m s g$ & $\begin{array}{l}\text { Pesan yang disampaikan pada log } \\
\text { ketika operator dalam rule ini } \\
\text { terdeteksi. }\end{array}$ \\
\hline logdata & Menyimpan hasil deteksi pada log. \\
\hline Tag,\severity & $\begin{array}{c}\text { Memberikan informasi tambahan } \\
\text { pada log }\end{array}$ \\
\hline
\end{tabular}

\subsection{Tahap Pengujian}

Pengujian dilakukan dengan dua tahapan yaitu Tahap Pertama ketika website sebelum di implementasikan web application firewall didalamnya, dan Tahap Kedua yaitu ketika website sesudah diimplementasikan web application firewall didalamnya. Pengujian serangan dilakukan dengan menggunakan 2 tools yang berbeda yaitu SQLMap \& JSQLInjection untuk melakukan serangan SQL Injection secara otomatis pada website.

Pada pengujian serangan dengan menggunakan menggunakan tools SQLMap dilakukan secara otomatis, penyerang hanya menunggu tools tersebut bekerja hingga mendapatkan hasilnya. Pada pengujian tahap pertama SQLMap berhasil melakukan eksploitasi serangan $S Q L$ injection terhadap website. Terlihat teknik yang digunakan untuk melakukan injeksi yaitu menggunakan time-based blind (query SLEEP). Adapun payload yang dikirimkan oleh SQLMap yaitu "id=51 AND (SELECT 7913 FROM (SELECT(SLEEP(5)))AGXw)"

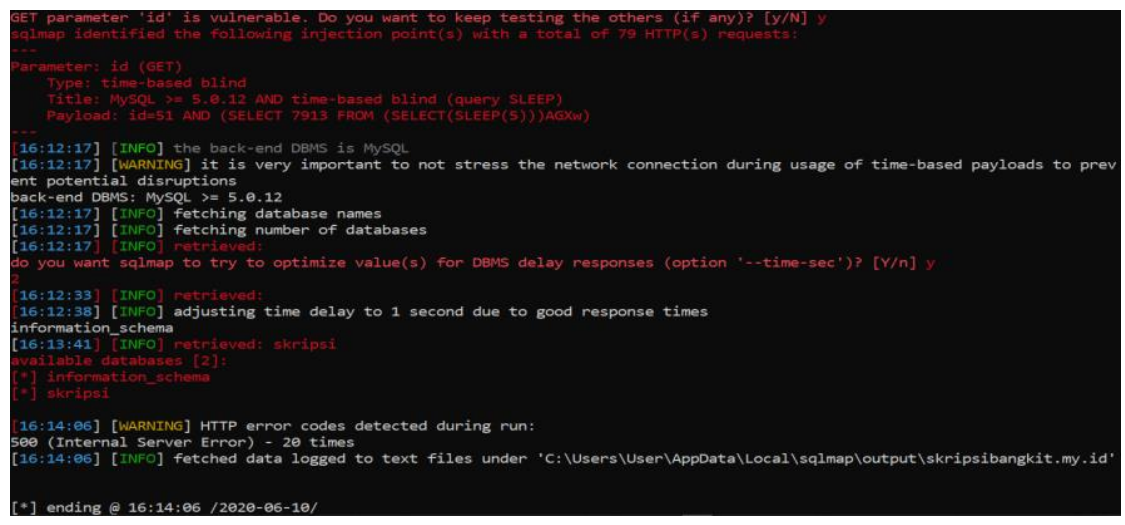

Gambar 5. Pengujian SQLMap pada tahap pertama 
Pada pengujian serangan tahap kedua, SQLMap gagal dalam melakukan eksploitasi serangan SQL injection terhadap website. Terlihat bahwa SQLMap mendeteksi website target terlindungi oleh WAF/IPS, sehingga ketika SQLMap mencoba melakukan eksploitasi lebih lanjut lagi proses ini terhambat dan SQLMap gagal dalam mendapatkan data ataupun informasi apapun yang terdapat pada website.

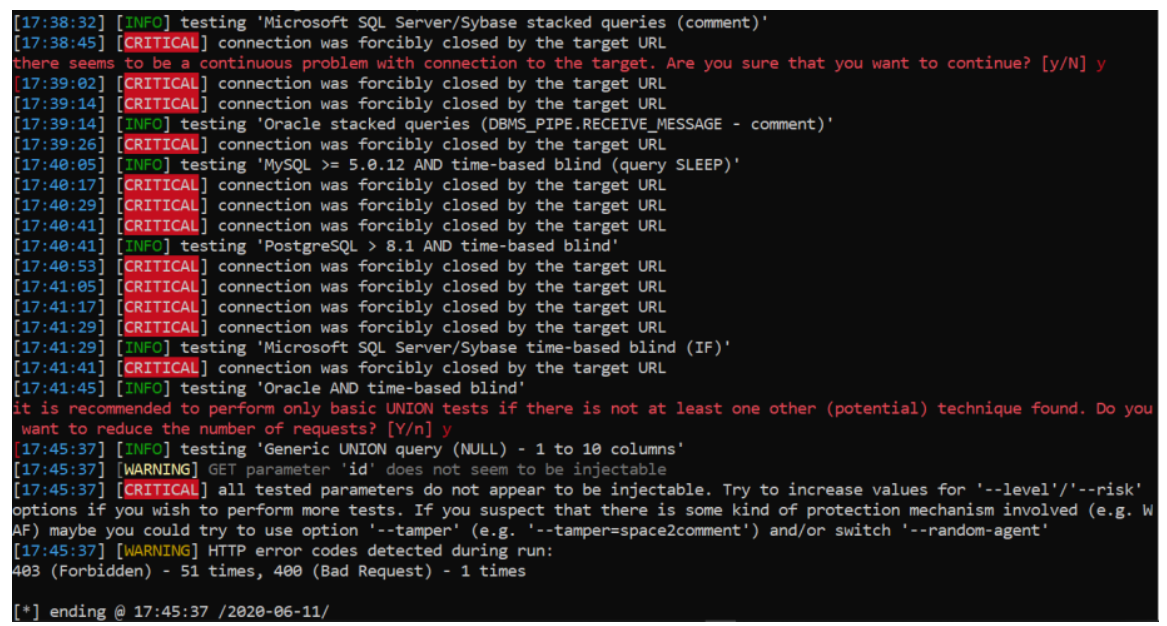

Gambar 6. Pengujian SQLMap pada tahap kedua

Selanjutnya pengujian serangan dilakukan dengan menggunakan menggunakan tools JSQLInjection, berbeda dengan SQLMap yang berbasis command line interface (CLI), JSQLInjection memiliki tampilan yang dapat mempermudah penyerang dalam mengeksekusi serangan. Pada pengujian tahap pertama JSQLInjection berhasil melakukan eksploitasi serangan $S Q L$ injection terhadap website, dan mendapatkan informasi penting yang terdapat didalam website target, seperti database, table, dan masih banyak lagi. Adapun payload yang dikirimkan oleh JSQLInjection beragam, salah satu dari sekian banyak payload yang dikirimkan oleh JSQLInjection yaitu :

"http://skripsibangkit.my.id/baca.php?id=51+union+select+1,1,1,1,(select+concat $(0 x 53714 c 6$ 9,mid((select+concat(group_concat $(0 \times 04, r, 0 x 05,1,0 x 04+o r d e r+b y+r+$ separator+0x06),0x0103 0307)from(select+cast(TABLE_NAME+as+char)r,cast(ifnull(table_rows,0x30)as+char)q+fro m+information_schema.tables+where+TABLE_SCHEMA=0x696e666f726d6174696f6e5f736 $368656 d 61+o r d e r+b y+r+l i m i t+47,65536) x), 1,82321))), 1,1,1,1--+”$

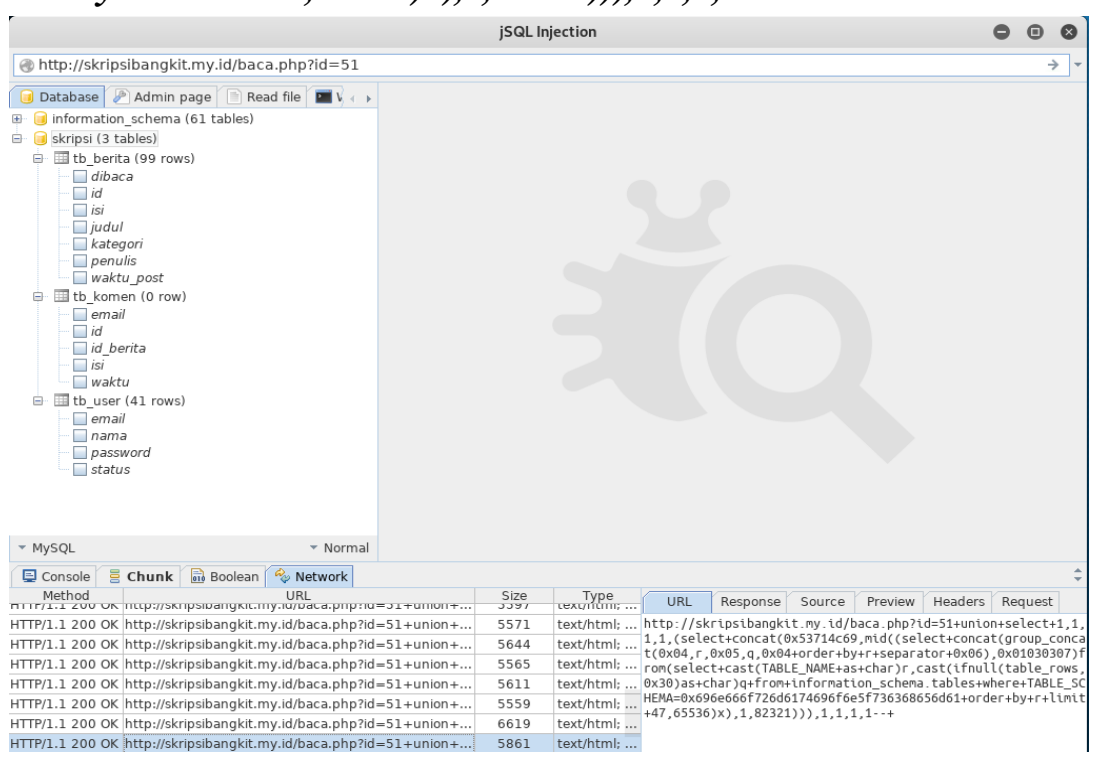

Gambar 7. Pengujian JSQLInjection pada tahap pertama 
Pada pengujian serangan tahap kedua JSQLInjection tidak berhasil melakukan serangan SQLInjection pada website target, terlihat bahwa hasil yang dikembalikan oleh JSQLInjection yaitu "No Injection Found", sehingga JSQLInjection tidak berhasil memperoleh informasi apapun yang terdapat pada website.

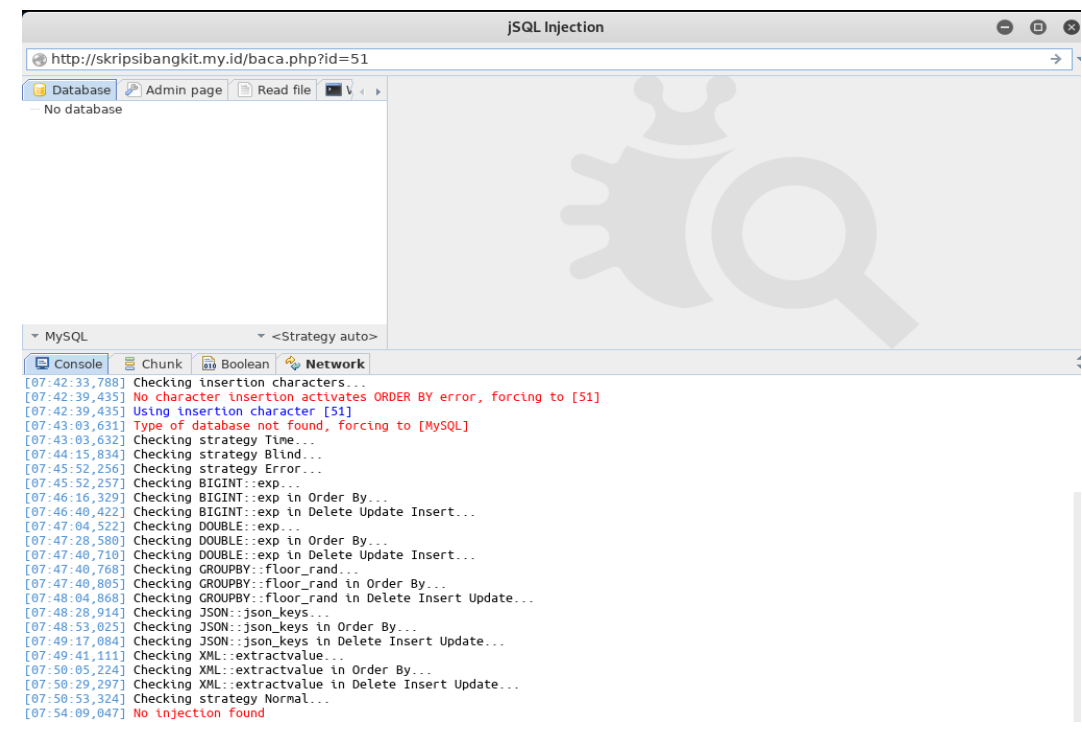

Gambar 8. Pengujian JSQLInjection pada tahap kedua

Kemudian pengujian dilakukan dengan menggunakan tools yang bernama Web Stress untuk mensimulasikan ketika website diakses oleh banyak user dalam waktu yang bersamaan, pengujian ini dilakukan dengan kondisi sebagai berikut :

1. Pengujian dilakukan dengan mensimulasikan 20 user

2. Simulasi dilakukan dengan waktu 1 menit

Adapun pengujian ini dilakukan untuk mengetahui load time dari website, ada dua tahapan dari pengujian ini yaitu ketika website sebelum dan sesudah menerapkan Web Application Firewall didalamnya. Hal ini dilakukan guna mengetahui perbandingan hasil yang didapat, Berikut ini merupakan tabel hasil yang didapatkan setelah pengujian berhasil dilakukan:

Tabel 5. Hasil Pengujian Performansi

\begin{tabular}{cccc}
\hline Simulasi Pengujian & Min & Max & Average \\
\hline Tanpa WAF & $67 \mathrm{~ms}$ & $108 \mathrm{~ms}$ & $78.9 \mathrm{~ms}$ \\
Menggunakan WAF & $102 \mathrm{~ms}$ & $161 \mathrm{~ms}$ & $115.9 \mathrm{~ms}$ \\
\hline
\end{tabular}

Dari hasil pengujian tersebut dapat dilihat bahwa load time dari website meningkat dari sebelum menggunakan mod security WAF dan sesudah menggunakan mod security WAF. Berbeda dengan penelitian yang dilakukan oleh robinson et all [14] bahwa load time dari menggunakan OWASP WAF didapatkan average sekitar 5,028Ms dengan menggunakan 100 user simulasi selama 1 menit.

\subsection{Hasil Pengujian}

Sistem pencegahan serangan SQL Injection pada penelitian ini terdiri dari Web Application Firewall dengan menggunakan Modsecurity yang telah dikonfigurasikan. System ini berfungsi untuk mencegah serta membatasi akses penyerang yang mengeksekusi serangan SQL injection pada website.

Dalam implementasinya, Web Application Firewall dapat berfungsi dengan baik, hal ini dibuktikan ketika dilakukan perbandingan hasil dari dua tahapan penyerangan yang di ujicoba kan, yaitu Tahap Pertama ketika website sebelum di implementasikan web application firewall 
didalamnya, dan Tahap Kedua yaitu ketika website sesudah diimplementasikan web application firewall didalamnya.

Dalam proses pengujian serangan diuji coba dengan menggunakan 2 tools yang berbeda yaitu SQLMAP \& JSQLInjection untuk melakukan serangan SQL Injection secara otomatis pada website. Adapun untuk hasil pengujian serangan menggunakan tools SQLMap \& JSQLInjection dapat dilihat melalui table berikut.

Tabel 6. Hasil Pengujian Serangan

\begin{tabular}{ccc}
\hline Hasil & Tahap Pertama & Tahap Kedua \\
\hline SQLMap & Berhasil & Gagal \\
JSQLInjection & Berhasil & Gagal \\
\hline
\end{tabular}

Dalam pengujian serangan menggunakan SQLMap \& JSQLInjection pada tahap kedua, dua tools tersebut Gagal dalam mendapatkan data maupun informasi yang terkandung didalam website target, factor ini disebabkan karena website yang dijadikan target telah mengimplementasikan security system didalamnya, sehingga dapat mencegah serangan yang dilakukan oleh dua tools tersebut.

Hal ini berbanding terbalik ketika pengujian dilakukan pada tahap pertama dimana dua tools tersebut Berhasil mendapatkan informasi maupun data yang terkandung didalam website target yang disebabkan karena website target belum mengimplementasikan security system didalamnya, oleh karena itu celah injeksi masih terbuka lebar sehingga dua tools tersebut dapat dengan mudahnya mengeksploitasi celah injeksi pada website target.

Hasil pengujian oleh Robinsin et all [14] dengan menggunakan OWASP WAF juga mendapatkan hasil yang sama dengan penelitian ini bahwa serangan SQL injection dapat di tangani dengan baik, begitu juga pengujian yang di lakukan oleh risma et all [19] bahwa dengan menggunakan WAF Naxsi untuk linux mint dapat mengidentifikasi serangan pada web.

Pada pengujian performansi juga terdapat dua tahapan simulasi yang dilakukan sama seperti pada saat pengujian serangan. Pengujian performansi ini dilakukan untuk mengetahui apakah penerapan web application firewall dapat mempengaruhi load time yang dapat memperlambat user dalam mengakses website atau tidak.

Dari pengujian yang sudah dilakukan, simulasi pada tahap 1 mendapatkan rata rata load time lebih cepat yang ditandai dengan garis grafik yang lebih rendah dibandingkan dengan simulasi pada tahap 2. Hasil yang didapatkan pada pengujian tahap dua menjadi lebih lama, hal ini disebabkan karena adanya factor pengecekan pada setiap permintaan yang menuju ke website yang dilakukan oleh Web Application Firewall sehingga waktu yang dibutuhkan sedikit lebih lama. Ini sama dengan hasil penelitian yang dilakukan oleh Robinson et all [14] bahwa pada OWASP WAF ada perbedaan waktu pada loadtime HTTP. Hal ini dibuktikan pada grafik berikut ini.

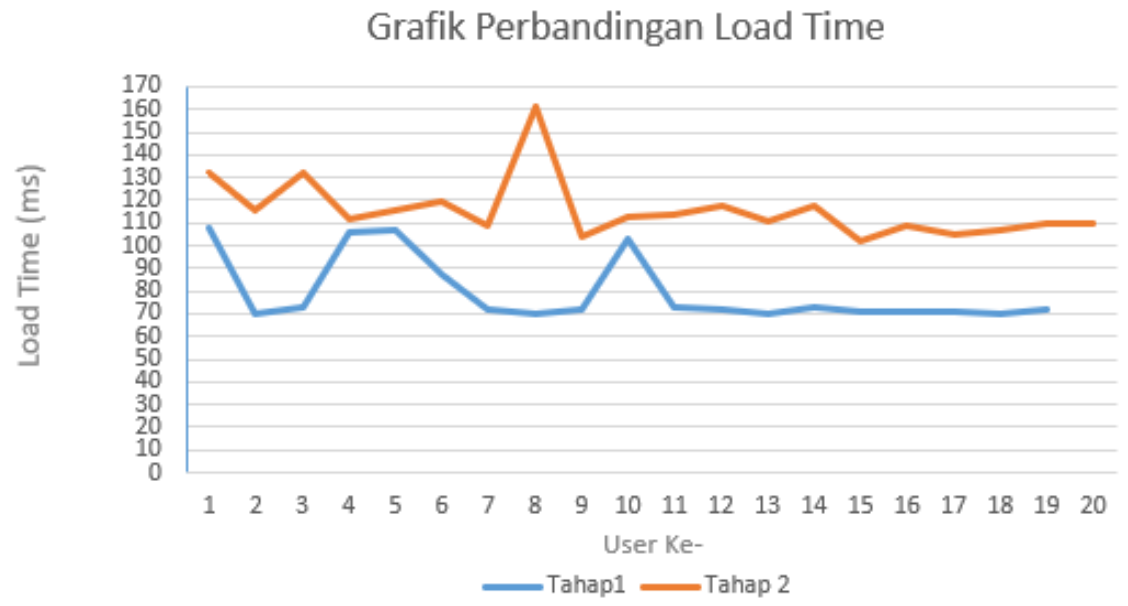

Gambar 9. Grafik Perbandingan Load Time Pengujian Tahap 1 dan Tahap 2 


\section{Kesimpulan}

Dari hasil pengujian dan analisa terhadap penggunaan Web Application Firewall didapatkan beberapa temuan yaitu dengan menggunakan Web Application Firewall pada mod security maka loadtime untuk website akan semakin lama. Ini dikarenakan sistem security pada WAF akan mencek setiap akses yang masuk, sebelum diteruskan ke dalam website. Untuk itu user akan membutuhkan waktu untuk menerima halaman web yang direquest kepada server. Walaupun ada perbedaan load time (ms) antara memakai OWASP WAF dan Mod Security WAF, tetapi dalam waktu rata-rata load time HTTP secara nyata tidak mempengaruhi performansi dari web tersebut.

Berdasarkan hasil ujicoba serangan, implementasi Web Application Firewall mampu meminimalisir serangan $S Q L$ Injection dikarenakan dalam tools mod security ini sistem akan berfungsi membatasi penyerang untuk mengeksekusi SQL Injection dalam sebuah website, sehingga hasil pengujian ini menunjukkan penyerang tidak mendapatkan informasi apapun yang terkandung di dalam website karena di dalam sistem security ini mengurangi celah-celah yang terbuka untuk dieksploitasi lebih dalam lagi.

\section{Daftar Pustaka}

[1] B. Raharjo, I. Heryanto, and K. ER, Modul Pemrograman Web (HTML; PHP; MySql) Revisi Kedua. Bandung: Modula, 2014.

[2] S. Latha and S. J. Prakash, "A survey on network attacks and Intrusion detection systems," 2017 4th Int. Conf. Adv. Comput. Commun. Syst. ICACCS 2017, 2017, doi: 10.1109/ICACCS.2017.8014614.

[3] M. Thiyab, M. Ali, and F. Basil, "The Impact of SQL Injection Attacks on the Security of Databases," Proc. 6th Int. Conf. Comput. Informatics, no. 080, pp. 323-331, 2017.

[4] J. Clarke, SQL Injection Attacks and Defense, 2nd Editio. United Kingdom: Syngress, 2012.

[5] V. Dehalwar, A. Kalam, M. L. Kolhe, and A. Zayegh, "OWASP Top 10 - 2017, The Ten Most Critical Web Application Security Risks," 2018. doi: 10.1109/ICPES.2017.8387407.

[6] A. M. Damar, "Polisi Ringkus Hacker Surabaya yang Bobol 44 Negara," 2018. .

[7] N. Avital, "The State of Web Application Vulnerabilities in 2018," 2018. .

[8] J. J. Singh, H. Samuel, and P. Zavarsky, "Impact of paranoia levels on the effectiveness of the modsecurity web application firewall," Proc. - 2018 1st Int. Conf. Data Intell. Secur. ICDIS 2018, pp. 141-144, 2018, doi: 10.1109/ICDIS.2018.00030.

[9] J. P. Singh, “Analysis of SQL Injection Detection Techniques," pp. 1-10, 2016.

[10] A. K. Dalai and S. K. Jena, "Neutralizing SQL injection attack using server side code modification in web applications," Secur. Commun. Networks, vol. 2017, 2017, doi: $10.1155 / 2017 / 3825373$.

[11] U. Upadhyay and G. Khilari, "SQL injection avoidance for protected database with ASCII using SNORT and HONEYPOT," Int. Conf. Adv. Commun. Control Comput. Technol., no. 978, pp. 596-599, 2016, doi: 10.1109/ICACCCT.2016.7831710.

[12] A. Maraj and E. Rogova, "Testing Techniques and Analysis of SQL Injection Attacks," Int. Conf. Knowl. Eng. Appl., vol. 12, no. 1, p. 145, 2017.

[13] V. Clincy and H. Shahriar, "Web Application Firewall: Network Security Models and Configuration," Proc. - Int. Comput. Softw. Appl. Conf., vol. 1, pp. 835-836, 2018, doi: 10.1109/COMPSAC.2018.00144.

[14] Robinson, M. Akbar, and Muhammad Arif Fadhly Ridha, "SQL Injection and Cross Site Scripting Prevention Using OWASP Web Application Firewall," Int. J. Informatics Vis., vol. 2, pp. 286-292, 2018. 
[15] H. M. Z. Al Shebli and B. D. Beheshti, "A study on penetration testing process and tools," 2018 IEEE Long Isl. Syst. Appl. Technol. Conf. LISAT 2018, pp. 1-7, 2018, doi: 10.1109/LISAT.2018.8378035.

[16] I. Ristic and C. Folini, Modsecurity Handbook - The Complete Guide to the Popular Open Source Web Application Firewall. 2017.

[17] G. R. K. Rao and D. R. S. Prasad, "Combating Cross-Site Scripting Assaults without Proprietary Software," Int. J. Appl. Eng., vol. 12, no. 17, pp. 6788-6796, 2017.

[18] A. Alamsyah and T. A. Cahyanto, "ANALISA KEAMANAN INFORMASI PADA APLIKASI BERBASIS WEB MENGGUNAKAN TEKNIK WEB APPLICATION FIREWALL MODSECURITY," 2016.

[19] R. Yanti Jamain, Periyadi, and S. Juli Irza Ismail, "Implementasi Keamanan Aplikasi Web Dengan Web Application Firewall," e-Proceeding Appl. Sci., vol. 1, no. 3, pp. 2191-2195, 2015. Creative Commons Attribution International (CC BY-SA 4.0) 